\title{
DESENVOLVIMENTO DE IMUNÓGENO CONJUGADO DE LIPOPOLISSACARÍDEO DE PSEUDOMONAS AERUGINOSA E TOXÓIDE TETÂNICO
}

\author{
Bruno Gavinho', Rosangela Rodrigues dos Santos², Luiz Felipe Caron'1, Maria Rita \\ Sierakowski ${ }^{1}$, Lucy Ono ${ }^{1}$
}

\author{
1 UFPR \\ 2 CDME-SEAB-PR \\ Correspondência: Lucy Ono: lucy_ono2003@yahoo.com.br
}

RESUMO: O lipopolissacarídeo (LPS) de Pseudomonas aeruginosa foi conjugado ao toxóide tetânico (TT, toxina inativada do Clostridium tetani) utilizando a técnica de aminação redutiva direta, para o desenvolvimento de uma vacina conjugada (LPS-TT). Avaliou-se a resposta imune in vivo após aplicações intraperitoneais do imunógeno LPS-TT em camundongos Swiss, administrando-se 4 aplicações de LPS-TT com intervalos entre as doses de 14 dias. Avaliou-se o título de anticorpos anti-Pseudomonas produzidos pela técnica de soroaglutinação microscópica. Os grupos que foram imunizados com LPS-TT e com LPS+TT (não conjugado quimicamente) apresentaram resposta de anticorpos aglutinantes superior ao controle imunizado apenas com LPS, e a resposta após o reforço vacinal dos animais imunizados com o conjugado LPS-TT foi $567 \%$ superior ao dos animais imunizados com LPS.

Palavras-chave: aminação redutiva; imunização; soroaglutinação; vacina conjugada

\section{DEVELOPMENT OF A CONJUGATED IMMUNOGEN OF PSEUDOMONAS AERUGINOSA LIPOPOLYSACCHARIDE AND TETANUS TOXOID}

\begin{abstract}
The lipopolysaccharide (LPS) from Pseudomonas aeruginosa was conjugated to tetanus toxoid (TT, inactivated toxin from Clostridium tetani) using the direct reductive amination technique, to develop a conjugate vaccine (LPS-TT). The immune response was evaluated in vivo after intraperitoneal injections of the immunogen LPS-TT in Swiss mice, by administration of 4 injections of LPS-TT with the time between applications being 14 days. The title of anti-Pseudomonas antibodies was evaluated by microscopic seroagglutination test. The groups which were immunized with LPS-TT and LPS+TT (non-chemically conjugated) presented a response of agglutinating antibodies higher than the control immunized with LPS only, and the booster response of the animals immunized with the conjugate LPS-TT was $567 \%$ higher than in the animals immunized with LPS.
\end{abstract}

Key Words: reductive amination; immunization; seroagglutination; conjugate vaccine 


\section{INTRODUÇÃO}

Pseudomonas aeruginosa é uma bactéria Gram-negativa ubíqua, encontrada em águas frescas e no solo (Döring e Pier, 2008). Está apta a colonizar uma grande diversidade de nichos, e é uma das principais fontes de infecções nosocomiais, juntamente com os estafilococos coagulase-negativos, como Staphylococcus spp. e Enterococcus spp. Contaminações ocorrem a partir de fontes comuns como respiradores, umidificadores, reservatórios de água e alimentos, assim como transmissões por contato direto nas Unidades de Tratamento Intensivo (Kerr e Snelling, 2009).

É um clássico patógeno oportunista, que normalmente não representa ameaça ao indivíduo imunocompetente, sendo eliminando através de opsonização e fagocitose. Porém, pacientes hospitalizados, como transplantados e pacientes com queimaduras extensas são um grupo altamente susceptível à infecção por $P$. aeruginosa (Lee et al., 2000).

$\mathrm{Na}$ saúde animal, a bactéria já foi identificada em diversas manifestações clínicas, em mamíferos e aves. Nos cães, $P$. aeruginosa é uma causa comum de pioderma, otites média e externa, e infecções do trato urinário (Gatoria et al., 2006; Hariharam et al., 2006; Hillier et al., 2006). Hawkins et al. (2010) afirmam que clínicos de pequenos animais possuem pouco sucesso em casos de otite, até mesmo quando agentes antimicrobianos são sensíveis à estirpe. A espécie é um dos patógenos mais isolados de otoscópios após exames clínicos em cães, mesmo após o processo de desinfecção com amônias quaternárias. $O$ instrumento comporta-se como vetor para transmissão em animais saudáveis (Kirby et al., 2010). Westgate et al. (2011) estudaram as populações de patógenos isolados de feridas crônicas de equinos, sendo a $P$. aeruginosa a espécie mais isolada de feridas cirúrgicas. Estes tecidos teriam difícil cicatrização, pela produção de biofilmes destes patógenos. Infecções já foram relatadas na avicultura, resultando em alta mortalidade e septicemia (Monotani et al., 1995).

Além disso, para os pacientes humanos portadores de fibrose cística, nos quais há uma mutação no gene CFTR (cystic fibrosis transmembrane conductance regulator) que codifica uma proteína transmembrana ligada a canais de cloro, há prejuízo do transporte de sais e água das células da via respiratória (Bobadilla et al., 2002), o que resulta no acúmulo de muco espesso, dificultando a eliminação de bactérias dos pulmões. Episódios recorrentes de infecção e inflamação, como as causadas pela $P$. aeruginosa levam à destruição do tecido pulmonar.

$P$. aeruginosa possui resistência intrínseca a diversas classes de antibióticos, limitando as opções terapêuticas. A resistência a uma mesma classe de antibióticos pode ser mediada por vários mecanismos (Kerr e Snelling, 2009). Embora antibióticos estejam disponíveis, a capacidade da bactéria em desenvolver multirresistência a compostos químicos compromete o tratamento de pacientes. Como casos de multirresistência a drogas são cada vez mais relatados (Engels e Balachandran, 2009), isso indica a importância do desenvolvimento de vacinas eficazes. Leitner e Krifucks (2007) Sugerem que a vacinação de bovinos com produto inativado pode reduzir infecções por $P$. aeruginosa.

A indução de anticorpos contra estruturas de membrana da $P$. aeruginosa é T-independente, pelo fato dos antígenos induzirem a produção de anticorpos por uma via independente de linfócitos T-auxiliares, não ativando células B para geração de memória. Antígenos T-independentes são 
geralmente moléculas grandes, com múltiplas repetições de subunidades, como os lipídeos e carboidratos da membrana externa de bactérias Gramnegativas. A geração de memória imunológica pode ser induzida quando antígenos são transformados em Tdependentes, pela sua conjugação com uma proteína. Esta resposta imune, que envolve o conjugado polissacarídeoproteína, tem início no momento da captura deste complexo por células dendríticas. Estas células, ao dirigiremse para os tecidos linfóides secundários, internalizam o conjugado, degradandoos em peptídeos, e expondo-os ao complexo principal de histocompatibilidade de classe II (MHCII), para interação com células $T$ específicas (Plotkin e Orenstein, 2003).

Baseando-se nas pesquisas com vacinas conjugadas, este trabalho avaliou a conjugação do lipopolissacarídeo de Pseudomonas aeruginosa, um antígeno Tindependente com toxóide tetânico (neurotoxina quimicamente inativada de Clostridium tetani), um antígeno Tdependente, por meio de aminação redutiva direta, visando a obtenção de memória imunológica contra o lipopolissacarídeo de $P$. aeruginosa.

\section{MATERIAL E MÉTODOS}

$\begin{aligned} & \text { Produção de } \\ & \text { aeruginosa } \\ & \text { Utilizou-se a }\end{aligned}$ Pseudomonas
aeruginosa, cepa 27853. Para a
confirmação da espécie, colônias foram
semeadas em ágar Cetrimida e foram
realizadas provas bioquímicas para
identificação de bactérias Gram-
negativas não-fermentadoras.

Para a produção de massa bacteriana (a ser utilizada para a extração de LPS), a bactéria foi cultivada em ágar Sangue, a $37^{\circ} \mathrm{C}$, por 24 horas. Para tanto, cada placa de ágar utilizada para produção da bactéria recebeu um inóculo de $1 \mathrm{~mL}$ do tubo 0,5 da escala de Mac Farland $\left(1,5 \times 10^{8}\right.$ unidades formadoras de colônia). Após o crescimento, foram realizadas suspensões (solução $\mathrm{NaCl}$ 0,85\%) de cada meio, centrifugadas a $3220 \mathrm{~g}$, por 20 minutos, a $8^{\circ} \mathrm{C}$. Após 0 procedimento, o conteúdo centrifugado passou por duas lavagens com água destilada, e foi novamente centrifugado.

Para a inativação química, uma suspensão das colônias em solução salina $(\mathrm{NaCl} \quad 0,85 \%)$ esterilizada foi preparada e inativada com formaldeído $37 \%, 1: 5000(\mathrm{v} / \mathrm{v})$, por 24 horas a $8^{\circ} \mathrm{C}$. A confirmação da inativação foi observada pela ausência de crescimento quando uma amostra da suspensão foi semeada e incubada a $37^{\circ} \mathrm{C}$ por $24 \mathrm{~h}$.

\section{Extração de lipopolissacarídeo}

A extração de LPS de $P$. aeruginosa foi realizada segundo protocolo adaptado de Westphal e Jann (1965). Para extração, foram utilizados $352 \mathrm{mg}$ de Pseudomonas aeruginosa (336 x $10^{13}$ UFC). A suspensão bacteriana foi misturada com solução de fenol a $90 \%$ e água destilada $\left(350 \mathrm{~mL}, 65^{\circ} \mathrm{C}\right)$, sob agitação, por 15 minutos. Em seguida centrifugou-se a suspensão a $2630 \mathrm{~g}$, a $10^{\circ} \mathrm{C}$, durante 40 minutos. Coletou-se o sobrenadante, tratando novamente as frações restantes com água quente, repetindo o processo mais duas vezes. Após extração, o sobrenadante coletado foi dialisado contra água destilada, realizando-se trocas periódicas, por 4 dias.

\section{Conjugação do LPS ao toxóide tetânico}

Para a conjugação do LPS de $P$. aeruginosa com o toxóide tetânico (TT), foi utilizada a técnica de aminação redutiva direta, adaptado de Shen et al. (2001), em que o meta-periodato de sódio produz grupamentos aldeídos. $\mathrm{O}$ reagente TT foi gentilmente cedido pelo TECPAR, Curitiba - PR. Dissolveram-se $10 \mathrm{mg}$ de LPS em $20 \mathrm{ml}$ de água destilada, adicionado de $4 \mathrm{mM}$ de meta- 
Periodato de Sódio $\left(\mathrm{NalO}_{4}\right)$ sob agitação, em temperatura ambiente, ao abrigo da luz, durante 1,5 h. Em seguida, foi adicionado etileno-glicol mantendo a solução por mais 30 minutos nas mesmas condições. $O$ material foi então dialisado contra água destilada por 3 dias, em temperatura ambiente.

Após diálise foi adicionado bicarbonato de sódio $\left(\mathrm{NaHCO}_{3}\right) 0,1 \mathrm{M} \mathrm{e}$ $0 \mathrm{pH}$ ajustado para 8,5; em seguida solubilizaram-se $3,9 \mathrm{mg}$ de toxóide tetânico (TT), e finalmente adicionaramse $20 \mathrm{mg} / \mathrm{mL}$ de cianoborohidreto de Sódio $\left(\mathrm{NaCNBH}_{4}\right)$ sob agitação leve, ao abrigo da luz, a temperatura de $37^{\circ} \mathrm{C}$, por 5 dias. Após o tempo de incubação, $10 \mathrm{mg} / \mathrm{mL}$ de borohidreto de sódio $\left(\mathrm{NaBH}_{4}\right)$ foram solubilizados e deixou-se a solução em temperatura ambiente por $18 \mathrm{~h}$. Por final a solução foi dialisada contra água destilada por 4 dias, com duas trocas diárias de água.

\section{Análises do LPS, TT e do imunoconjugado LPS-TT}

As dosagens de açúcar (AT) e de proteína (PT) totais foram realizadas pelo método de Dubois et al. (1956) e pelo método de Bradford (1976), respectivamente. Para a avaliação da reação de conjugação, as amostras de LPS, TT e de imunoconjugado LPS-TT foram aplicadas separadamente em coluna de gel-permeação de Sepharose CL-4B, de $84 \mathrm{~cm}$ de altura com $1 \mathrm{~cm}$ de diâmetro, eluídas com solução salina ( $\mathrm{NaCl} 0,85 \%$ ) e alíquotas de $3 \mathrm{~mL}$ foram coletadas para dosagens de AT e PT, construindo-se os perfis de eluição. A sefarose é uma matriz utilizada para produtos de massa molar de 60 20.000 kDa para proteína, e $30-5.000$ kDa para açúcares. Utilizou-se o corante azul de dextrana para determinação de volume morto. Como controle, eluíramse cinco soluções dextroses-padrões de $10 \mathrm{mg}$, variando a massa molar de 71,6 $-2.000 \mathrm{kDa}$.

\section{Avaliação da resposta imune por meio da imunização experimental em camundongos}

Foram utilizados camundongos fêmeas Swiss, provenientes do biotério da Universidade Federal do Paraná, com idade entre 3 e 5 semanas. Os animais foram tratados com ração própria para camundongos e água filtrada ad libitum.

Os animais foram divididos em 4 grupos, com 6 camundongos cada, considerando o LPS como controle, e avaliou-se a resposta de LPS+TT (não conjugados), além do LPS-TT (imunógeno conjugado): Grupo 1 (controle solução $\mathrm{NaCl} 0,85 \%$ ); Grupo 2 (Controle LPS $20 \mu \mathrm{g} /$ dose); Grupo 3 (LPS $20 \mu \mathrm{g} /$ dose + TT) e Grupo 4 (LPSTT $20 \mu \mathrm{g} /$ dose).

Todos os controles e amostras foram adjuvados com gel de hidróxido de alumínio $1,5 \%$. O protocolo considerou aplicações com intervalos de duas semanas, totalizando quatro doses/animal, e quatro semanas após a última aplicação foram realizadas 7 coletas de sangue (via retro-orbital), em intervalos de $\sim 4$ semanas.

\section{Titulação de anticorpos}

A titulação dos anticorpos antiPseudomonas foi realizada pela técnica de soroaglutinação microscópica (SAM) em lâmina adaptada de Laborde e Fajardo (1969). O antígeno foi preparado com a suspensão de uma cultura de $P$. aeruginosa (cepa ATCC $27853)$ em solução salina ( $\mathrm{NaCl} 0,85 \%)$ até atingir opacidade equivalente na escala 10 de Mc Farland a $3 \times 10^{9} \mathrm{UFC} / \mathrm{mL}$.

Volumes iguais do soro-teste e da suspensão bacteriana foram misturados em lâmina de vidro, em temperatura ambiente, e a leitura da aglutinação se dava no tempo máximo de 10 minutos. Foram realizadas diluições seriadas do soro com fator de diluição de 2 vezes para a determinação do título de aglutinação, que é definido como sendo 

aeruginosa e toxóide tetânico

a maior diluição da amostra onde ocorre reação positiva.

\section{Eutanásia}

Todo procedimento de eutanásia foi realizado sob protocolo de anestesia com cloridrato de xilazina $2 \%$ e cloridrato de quetamina $10 \%(1: 1)$ via intraperitoneal seguido de exossanguese ou injeção de cloreto de potássio $10 \%$, via intracardíaca.

\section{Análise estatística}

Para avaliar a diferença significativa entre os títulos de anticorpos dos grupos teste e controle inoculado apenas com LPS $\mu \mathrm{g} /$ dose (grupo G2), foi aplicado o teste $\mathrm{H}$ não-paramétrico de KruskalWallis, seguido do teste de DunnBonferroni, com $\mathrm{P}<0,01$ para comparações múltiplas entre os grupos experimentais (2 a 2).

\section{RESULTADOS E DISCUSSÃO}

Neste trabalho, utilizou-se o lipopolissacarídeo (LPS) de Pseudomonas aeruginosa para a síntese do imunoconjugado carboidratoproteína por ser o componente mais imunogênico de bactérias Gramnegativas, apesar de ser pirogênico dependendo da dose (Holder, 2004).

Para extração do LPS foram utilizados $352 \mathrm{mg}$ de Pseudomonas aeruginosa $\left(336 \times 10^{13}\right.$ UFC), e, considerando 0 produto final da extração, a execução do protocolo adaptado de Shen et al. (2001) apresentou rendimento de $2,8 \%$, comparável aos resultados já descritos por Santos et al. (2009), que extraíram LPS com rendimento de 1,5\%. Al-Zeer et al. (2007) citam valores de rendimento de extração de LPS entre 24\%. Cryz et al. (1986) conjugaram LPS a toxóide tetânico (TT), mas não citaram valores de rendimento. O princípio da extração de LPS de bactérias com o protocolo fenol-água quente utiliza a capacidade do fenol em desnaturar as proteínas das células, e assim romper a ligação do lipopolissacarídeo com a membrana externa (dissociação do antígeno somático O). O LPS e os ácidos nucléicos preservados são coletados no sobrenadante de extração, após dissociação do complexo antígeno somático (polissacarídeo $O$ ) da parede bacteriana (Westphal e Jann, 1965).

A conjugação do LPS de Pseudomonas aeruginosa ao toxóide tetânico (LPS-TT) foi realizada por meio de aminação redutiva direta, em que a molécula a ser conjugada, no caso, o LPS, tem seus grupos hidroxila oxidados, resultando em grupos aldeído. Os aldeídos recém-formados têm alta capacidade de interação com proteínas, e através de ligação amina, o protocolo permite a obtenção de um conjugado com uma proteína de escolha, como o toxóide tetânico.

Foram realizadas dosagens de açúcar (AT) e de proteína (PT) totais para a caracterização química inicial de LPS e do imunoconjugado sintetizado LPS-TT, determinando-se para LPS as concentrações de AT: $549,5 \mu \mathrm{g} / \mathrm{mL}$ e PT: $40,5 \mu \mathrm{g} / \mathrm{mL}$; para o imunoconjugado LPS-TT de AT: $125,8 \mu \mathrm{g} / \mathrm{mL}$ e PT: 184,8 $\mu \mathrm{g} / \mathrm{mL}$.

Já a cromatografia de gel-permeação de LPS, TT e LPS-TT foi realizada para a comprovação da produção do imunoconjugado LPS-TT após a reação de aminação redutiva, pois por esta técnica, as moléculas eluem em volumes diferentes por uma coluna contendo matriz apropriada, de acordo com sua massa molecular. Em relação à eluição do LPS, a Figura 1 permite identificar 2 picos de detecção maior, seguido de vários menores, sugerindo que a maior parte do LPS tenha sido eluída a 10 e $50 \mathrm{~mL}$. Sabe-se que o LPS de Pseudomonas aeruginosa pode apresentar diferentes massas moleculares, dependendo do número de porções sacarídeas no polissacarídeo $O$ (Ag-O) (Goldberg e Pier, 1996). Portanto, é possível que os outros picos 
sejam resultado da eluição de frações de LPS que sofreram hidrólise durante a extração, ou seja, porções de LPS com número reduzido de resíduos de açúcar, em comparação com as frações eluídas em volumes menores. O TT apresentou distribuição regular, com pico definido em $40 \mathrm{~mL}$, indicando boa homogeneidade da amostra.

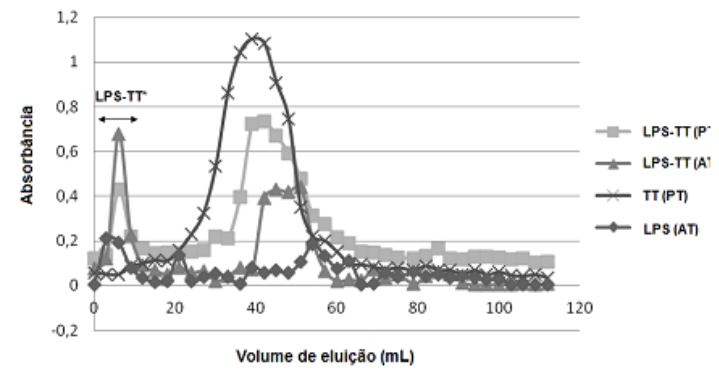

Figura 1 - Perfis de eluição de açúcar total (AT, $\lambda=490 \mathrm{~nm}$ ) e de proteína total (PT, $\lambda=540 \mathrm{~nm}$ ) do lipopolissacarídeo (LPS) de Pseudomonas aeruginosa, do toxóide tetânico (TT) e do conjugado LPS-TT após aplicação em coluna de gel-permeação (Sepharose Cl-4B, h: $84 \mathrm{~cm}$, $z=1 \mathrm{~cm}$, eluente: $\mathrm{NaCl} 0,85 \%)$. O volume morto da coluna desconsiderado para a construção do gráfico, foi de $22 \mathrm{~mL}$. *A seta indica a faixa de volume de eluição que provavelmente contém LPS e TT ligados covalentemente.

A Figura 1 também mostra a eluição do açúcar e proteína totais do imunoconjugado LPS-TT. A sobreposição dos 2 perfis de eluição sugere que o primeiro pico do açúcar e da proteína totais, ambos em torno de $10 \mathrm{~mL}$, representem a maior quantidade de LPS conjugado ao toxóide. Esta hipótese se baseia na diferença de volumes de eluição: o LPS-TT possui massa molar maior que o do TT e LPS separados, logo, acaba sendo eluído antes destes (o TT foi eluído aos 40 $\mathrm{mL}$ ). Os demais picos de detecção de cada curva sugerem a eluição do TT ou do LPS. Também é possível que estes demais picos apresentem LPS conjugado, mas é possível também que representem LPS ou TT parcialmente degradados durante a reação de conjugação.

Em relação à imunização, todos os animais, com exceção do Grupo 1 (animais inoculados com o veículo $\mathrm{NaCl}$ $0,85 \%$ ), apresentaram sinais de hipertermia e prostração dois dias após a aplicação dos imunógenos.
Houve diferença estatisticamente significativa $(P<0,01)$ entre o Grupo 2 (Controle LPS $20 \mu \mathrm{g} /$ dose) e o Grupo 3 (Controle LPS $20 \mu \mathrm{g} /$ dose + 29,4 $\mu \mathrm{g} /$ dose de TT), com o Grupo 3 apresentando título de anticorpos antiPseudomonas aeruginosa 177\% superior ao do controle, bem como entre o Grupo 2 e o Grupo 4 (Conjugado LPSTT $20 \mu \mathrm{g} /$ dose), com o Grupo 4 apresentando título $362 \%$ superior ao do controle, na $16^{\mathrm{a}}$ semana após a imunização, mantendo-se nas $23^{\text {a }}$ e $32^{a}$ semanas (Tab. 1 e 2, Fig. 2). Na 41aㅡ semana (4 semanas após a aplicação do reforço vacinal), o Grupo 4, que representa 0 imunoconjugado apresentou título de soroaglutinação 567\% superior ao Grupo 2.

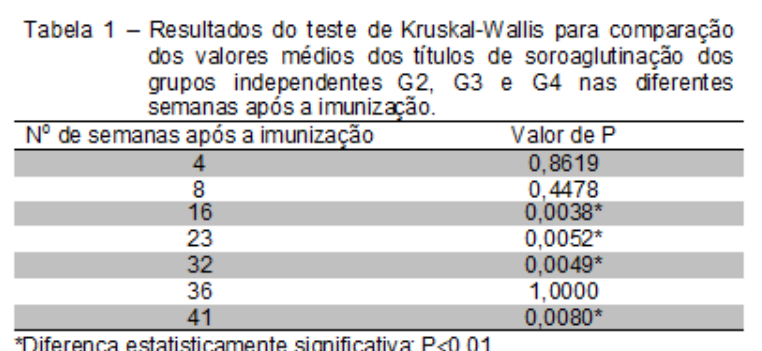

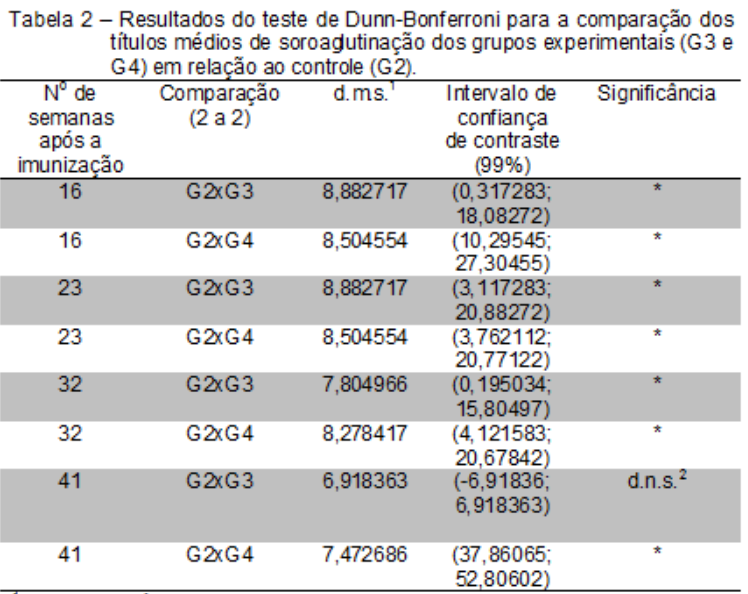

'Diferença mínima significativa; *Diferença estatisticamente significativa; $\mathrm{P}<0,01 ;{ }^{2}$ Diferença não significativa

Existem atualmente vacinas conjugadas de alta eficácia contra várias doenças bacterianas invasivas para crianças, incluindo aquelas causadas por Haemophilus influenzae tipo b (Hib), pneumococos e meningococos. O resultado da conjugação é uma resposta alta de IgG e geração de células de 

aeruginosa e toxóide tetânico

memória, mimetizando uma resposta imunológica a uma proteína (Frasch, 2009).

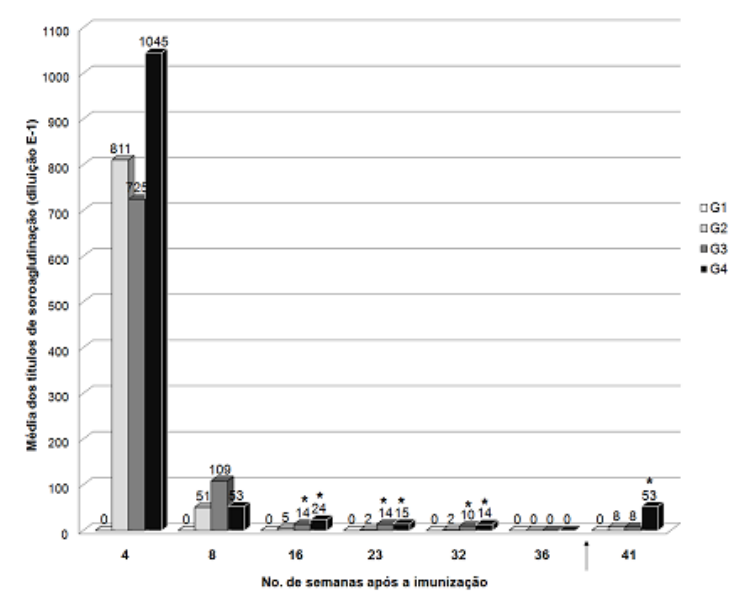

Figura 2 - Determinação dos títulos de soroaglutinação das amostras G1 (controle NaCl 0,85\%), G2 (Controle LPS $20 \mu \mathrm{g} /$ dose), G3 (Controle LPS $20 \mu \mathrm{g} /$ dose $+29,4 \mu \mathrm{g} /$ dose de TT) e G4 (Conjugado LPS-TT 20 $\mu g /$ dose), todos adjuvados com gel de hidróxido de alumínio, coletados $4,8,16,23,32,36$ e 41 semanas após a imunização. A seta indica que 0 reforço vacinal foi aplicado na $37^{2}$ semana. ${ }^{*}$ Diferença estatisticamente significativa em relação a G2, P 00,01 .

Considerando a resposta pós-reforço vacinal de LPS-TT, as diferenças de títulos de soroaglutinação obtidos indicam a presença de resposta anamnéstica (resposta imune maior e mais rápida), sugerindo que as moléculas foram aderidas ao MHC-II, para reagirem com linfócitos $\mathrm{T}$. Provavelmente, isto só seria possível se o LPS estivesse covalentemente ligado a um carreador proteico. Algumas hipóteses poderiam justificar por que 0 título de soroaglutinação pós-reforço vacinal não foi elevado, como uma baixa proporção açúcar-proteína, diminuindo a exposição destes antígenos ao MHC-II. Devido a vários picos de menor amplitude após a eluição do LPS, a Figura 1 sugere presença de moléculas de LPS degradado.

Vários métodos foram estudados para prevenção de infecções por $P$. aeruginosa, incluindo imunização passiva, com anticorpos policlonais e monoclonais, e imunização ativa, através de vacinas. Reconhecida como uma excelente alternativa à antibioticoterapia, pesquisas envolvendo vacinas são desenvolvidas para prevenção das infecções. Vacinas para $P$. aeruginosa são estudadas há mais de 30 anos, embora o progresso seja lento. De acordo com Döring (2010), diversas razões justificam a falta de progresso no desenvolvimento de uma vacina adequada para a espécie: 1) dificuldade em testar um produto em pacientes que utilizam um pesado protocolo de antibioticoterapia, 2) mecanismos defectivos na imunidade de portadores de fibrose cística e 3) pequena população de portadores de fibrose cística, tornando esses estudos de difícil realização.

Pesquisas envolvendo o uso de vacinas conjugadas já foram realizadas para $P$. aeruginosa, embora nenhum produto encontre-se disponível para uso. Cryz et al. (1986) conjugaram o antígeno alginato da espécie com exotoxina A. Este conjugado induziu alta resposta de anticorpos contra alginato e exotoxina A em coelhos. As imunoglobulinas promoveram opsonização e neutralização de cepas mucóides de $P$. aeruginosa, com resposta de neutrófilos. Kashef et al. (2006) conjugaram alginato ao toxóide tetânico, conferindo proteção em camundongos contra uma dose letal de $P$. aeruginosa. Cryz et al. (1989) desenvolveram um conjugado octavalente do Antígeno O (envolvendo os oito sorotipos mais freqüentes) à exotoxina A. Esta vacina, chamada Aerugen $^{\mathrm{TM} 1}$, conferiu proteção significativa após aplicação intramuscular em animais. Após a aplicação, estes foram desafiados com cepas de $P$. aeruginosa contidas na vacina. Também houve desafio intranasal com o conjugado, porém não se admitiu maior proteção por esta via. A vacina entrou em testes clínicos (fase 2), mas em 2006 os testes duplo-cegos

\footnotetext{
${ }^{1}$ Fabricante Crucell NV, Leiden - Holanda.
} 
foram finalizados, porque Aerugen $^{\mathrm{TM}}$ não demonstrou diferença significativa entre o grupo imunizado e um grupo controle (Döring e Pier, 2008).

Em 2009, SANTOS et al. produziram um imunógeno da bactéria levando em consideração seu LPS, conjugado à albumina bovina (BSA). Seguindo um protocolo de hiperimunização, o estudo não observou maior titulação do grupo conjugado em relação ao controle. O protocolo de hiperimunização consistiu em 3 vacinações por semana, por 3 semanas, e vacinações diárias na quarta semana. É possível que o contato excessivo com o antígeno tenha provocado tolerância imunológica. Provavelmente o uso de albumina como carreadora contribuiu para o resultado, pois esta proteína possui regiões assinatura comuns a várias espécies de mamíferos. É possível que esta molécula tenha sido reconhecida como própria pelo modelo animal.

O toxóide tetânico, proteína utilizada neste trabalho, é uma proteína favorável para uso em vacinas conjugadas, devido às propriedades inflamatórias e imunogênicas. É um composto derivado da neurotoxina quimicamente inativada de Clostridium tetani que se comportaria como proteína carreadora, sem comprometer a resposta imune ou causar efeitos adversos (Plotkin e Orenstein, 2003).

\section{CONCLUSÃO}

Este trabalho teve como objetivo conjugar o toxóide tetânico com o lipopolissacarídeo de Pseudomonas aeruginosa, um dos antígenos de maior interesse no desenvolvimento de vacinas contra essa bactéria. Vários estudos consagram o LPS como antígeno mais eficiente de $P$. aeruginosa, e de fato, foi produzido um imunógeno capaz de elicitar resposta imune. Além disso, o processo de conjugação foi simples, rápido e barato.
No entanto, embora os títulos de soroaglutinação após reforço vacinal tenham indicado a geração de memória imunológica, ainda há a necessidade de padronizar a proporção açúcar: proteína do imunoconjugado, bem como de melhorar a sua pureza para a administração in vivo.

\section{AGRADECIMENTO}

À Coordenação de Aperfeiçoamento de Pessoal de Nível Superior (CAPES - Ministério da Educação - Brasil) pelo auxílio financeiro.

\section{NOTAS INFORMATIVAS}

\section{A autorização para utilização dos animais nos procedimentos experimentais descritos neste trabalho foi concedida pelo Comitê de Ética em Experimentação Animal da UFPR (CEEA, certificado 416, de 01/12/2009).}

\section{REFERÊNCIAS}

\section{AL-ZEER, M.; MASOUD, H. LPS-based conjugate vaccines composed of $\mathrm{O}$ - polysaccharide from Pseudomonas aeruginosa IATS 6 and 11 bound to a carrier protein. World Journal of Microbiology and Biotechnology, v.23, n.11, p.1541-1549, 2007.}

BOBADILLA, J.L.; MACEK, M.J.; FINE, J.P. et al. Cystic Fibrosis: a worldwide analysis of the CFTR mutations- correlation with the incidence data and application to screening. Human Mutation, v.19, n.6, p.575-606, 2002.

BRADFORD, M.M. A. A rapid and sensitive method for the quantitation of microgram quantities of protein utilizing the principle of protein-dye binding. Analitycal Biochemistry, v.72, p.248-254, 1976.

CRYZ, S.J.; SADOFF, J.C.; FÜRER, E. Pseudomonas aeruginosa Polysaccharidetetanus toxoid conjugate vaccine: safety and immunogenicity in humans. The journal of infectious diseases, v.154, n.4, p.682-688, 1986.

DÖRING, G. Prevention of Pseudomonas aeruginosa infection in cystic fibrosis patients. 
Desenvolvimento de imunógeno conjugado de lipopolissacarídeo de pseudomonas aeruginosa e toxóide tetânico

International Journal of Medical Microbiology, v.300, n.8, p.573-577, 2010.

DÖRING, G.; PIER, G.B. Vaccines and Immunotherapy against Pseudomonas aeruginosa. Vaccine, v.26, n.8, p.1011-1024, 2008.

DUBOIS, M.; GILLES, K.A.; HAMILTON, J.K. et al. Colorimetric Method for determination of sugars and related substances. Analytical Chemistry, v.28, n.3, p.350-356, 1956.

ENGEL, J.; BALACHANDRAN, P.; Role of Pseudomonas aeruginosa type III effectors in disease. Current Opinion in Microbiology, v.12, n.1, p.61-66, 2009.

FRASCH, C.E. Preparation of bacterial polysaccharide-protein conjugates: Analytical and manufacturing challenges. Vaccine, v.27, n.46, p.6468-6470, 2009.

GATORIA, I.S.; SAINI, N.S.; RAI, T.S. et al. Comparison of three techniques for the diagnosis of urinary tractinfections in dogs with urolithiasis. Journal of Small Animal Practice, v.47, n.12, p.727-732, 2006.

HAWKINS, C.; HARPER, D.; BURCH, D. et al. Topical treatment of Pseudomonas aeruginosa otitis of dogs with a bacteriophage mixture: A before/after clinical trial. Veterinary Microbiology, v.146, n.3-4, p.309-313, 2010.

HARIHARAN, H.; COLES, M.; POOLE, D. et al. Update on antimicrobial susceptibilities of bacterial isolatesfrom canine and feline otitis externa. Canadian Veterinary. Journal, v.47, n.3, p.253-255, 2006.

HILLIER, A.; ALCORN, J.R.; COLE, L.K. et al. Pyoderma caused by Pseudomonas aeruginosa infection in dogs - 20cases. Veterinary

Dermatology, v.17, n.6, p.432-439, 2006.

HOLDER, I.A. Pseudomonas immunotherapy: a historical overview. Vaccine, v.22, p.831-839, 2004.

JOHANSEN, H.K.; ESPERSEN, F.; CRYZ, S.J. et al. Immunization with Pseudomonas aeruginosa vaccines and adjuvant can modulate the type of inflammatory response subsequent to infection. Infection immunology, v.62, p.3155,1994.

KASHEF,N.; BEHZADIAN-NEJAD, Q.; NAJARPEERAYEH, S. et al. Synthesis and characterization of Pseudomonas aeruginosa alginate-tetanus toxoid conjugate. Journal of Medical Microbiology, v.55, n.10, p.1441-1446, 2006.

KERR, K.G.; SNELLING, A.M. Pseudomonas aeruginosa: a formidable and ever-present adversary. Journal of Hospital Infection, v.73, n.4, p.338-344, 2009.

KIRBY, A.; ROSENKRANTZ, W.S.; GHUBASH, W.S. et al.Evaluation of cone disinfection techniques and contamination level in small animal private practice. Veterinary

Dermatology, v.21, n.2, p.175-183, 2010.

KLOUWENBERG, P.K.; BONT, L. Neonatal and Infantile Immune Responses to Encapsulated Bacteria and Conjugate Vaccines. Clinical and Developmental Immunology, v.10, n.1, p.1-10, 2008.

LABORDE, H.F. E FAJARDO, C.L. Obtention and assay of rabbit anti-Pseudomonas serum. Journal of Bacteriology, v.98, n.3, p.992-995, 1969.

LEE, N.; JUNG, S.B.; AHN, B.Y. et al. Immunization of burn-patients with a Pseudomonas aeruginosa outer membrane protein vaccine elicits antibodies with protective efficacy. Vaccine, v.18, n.18, p.1952-1961, 2000.

LEITNER, G. ; KRIFUCKS, O.Pseudomonas aeruginosa mastitis outbreaks in sheep and goat flocks: antibody production and vaccination in a mouse model. Veterinary Immunology and Immunopathology, v.119, n.3-4, p.198-203, 2007.

MONOTANI, E.; KIRYU, M.; OHSHIRO, M. et al. Granulomatous lesions caused by

Pseudomonas aeruginosa in the Ostrich (Struthio camelus). Journal of Comparative Pathology, v.112, p.272-282, 1995.

PIER, G.B. Promises and pitfalls of Pseudomonas aeruginosa lipopolysaccharide as a vaccine antigen. Carbohydrate Research, v.338, n.23, p.2549-2556, 2003.

PLOTKIN, A.S; ORENSTEIN, W.A. Vaccine, Philadelphia : W.B. Saunders, $4^{\text {a }}$ edição, 2003, $1408 \mathrm{p}$.

SANTOS, R.R. Desenvolvimento e estudo in vivo de uma vacina conjugada contra Pseudomonas aeruginosa. 2009. Curitiba, 50f. Dissertação: Mestrado em Microbiologia, Parasitologia e Patologia, Universidade Federal do Paraná.

SHEN, X.; LAGERGARD, T.; YANG, Y. et al. Preparation and preclinical evaluation of experimental group B streptococcus type III polysaccharide-cholera toxin $B$ subunit conjugate vaccine for intranasal immunization. Vaccine, v.19, p.850-861, 2001. 
WESTGATE, S.J.; PERCIVAL, S.L.;

KNOTTENBELT, D.C. et al. Microbiology of

equine wounds and evidence of bacterial

biofilms. Veterinary Microbiology, v.150, n.1-2,

p.152-159, 2011.

WESTPHAL, O.; JANN, K. Bacterial

Lipopolysaccharides - Extraction with phenolwater and further applications of the procedure.

Methods in Carbohydrate Chemistry, v.5,

p.83-91, 1965. 